\title{
Are Selective Angiograms the Answer for the High Risk Lumbar Epidural Steroid Injection.
}

\section{TO THE EDITOR:}

Glaser et al's critical analysis of transforaminal epidural steroid injections suggests that Kambin's triangle be used instead of the Safe triangle for targeting the compressed spinal nerve root with steroid injections. Glaser's belief is that entering Kambin's triangle, a less vascularized area, will decrease the possiblity of an intra arterial injection, and the risk of paralysis secondary to spinal cord ischemia, a black swan event.

As mentioned in the article, Kambin's triangle carries its own risk of intradiscal injection. While an intradiscal injection can be treated conservatively (like a post-dural puncture headache), if it progresses, more invasive treatments may be indicated (initially, an epidural blood patch). Although rare, intradiscal injection can lead to the development of discitis and ultimately osteomyelitis. Such a complication would require intravenous antibiotics through a PICC line for several weeks to avoid surgical intervention, such as a corpectomy and/or fusion. If surgery is required, it carries the risk of neurological damage. In light of the above, the superior approach, (Kambin's triangle or the Safe triangle), can only be determined through a randomized control study. Until such a study is performed and the data analyzed, no definitive declaration can be made. Such a study may reveal surprising results in which outcomes for pain control and adverse effects are different for the former and latter.

Candido at el (3) have already demonstrated outcome is the same for both paramedian and transforaminal lumbar epidural steroid injections, with less risks with the former approach. If a specific location is ideal, perhaps we should go back to the days when studying the vasculature of the spinal cord to provide additional clinical information was routine. Venograms were once used to diagnose displaced discs when myelograms were equivocal (4-6). Selective arteriograms were used to isolate critical feeding vessels from the aorta for lesions of the spinal cord and vertebral bodies $(7,8)$. However, even with arterial and venous mapping, patients with abnormal anatomy and post -surgical changes will still be at risk for intravascular injection. Knowing the vasculature of the target- 
ed vertebral nerve root may further decrease the risk of intravascular injection, allow for optimal injection technique, and better results for our patients.

Jacob J. Rauchwerger MD

Pain Management Center of Long Island

77 North Centre Avenue, Suite 202,

Rockville Centre, NY, 11570

75 North Country Road

Port Jefferson, NY, 11777.

E-mail: Jacob jeffrey74@hotmail.com
Kenneth D. Candido MD

Chairman and Professor

Department of Anesthesiology

Advocate Illinois Masonic Medical Center

836 W. Wellington Ave, Suite 4815

Chicago, IL, 60657

E-mail: kdcandido@yahoo.com

\section{References}

1. Glaser SE, Shah RV. Root cause analysis of paraplegia following transforaminal epidural steroid injections: the 'unsafe' triangle. Pain Physician 2010; 13:237-244.

2. Jasper JF. Lumbar retrodiscal transforaminal injection. Pain Physician 2007; 10:501-510.

3. Candido, KD, Raghavendra MS, Chinthagada M. A prospective evaluation of iodinated contrast flow patterns with fluoroscopically guided lumbar epidural steroid injections: the lat- eral parasagittal interlaminar epidural approach versus the transforaminal approach. Anesth Analg 2008; 106: 638644.

4. Drasin GF, Daffner RH, Sexton RF, at el. Epidural venography: diagnosis pf herniated lumbar intervertebral disc and other disease of the epidural space. $A m$ J Roentgenol 1976; 126: 1010- 1016.

5. Gershater R, Holgate RC. Lumbar epidural venography in the diagnosis of disc herniations. Am J Roentgenol 1976; 126: 992-1002.
6. Miller MH, Handel SF, Coan JD. Transfemoral lumbar epidural venography. Am J Roentgenol 1976; 126:1003-1009.

7. Djindjian R. Arteriography of the spinal cord. Am / Roentgenol 1969; 107 (3): 461-478.

8. Parke WW, Gammell K, Rothman RH. Arterial vascularization of the cauda equine. J Bone and Joint Surg AM 1981; 63:53-62. 